\title{
LOS PERÍODOS HIPOTÉTICOS COMO RECURSO ARGUMENTATIVO EN EPIGRAMAS ATRIBUIDOS A LUCIANO DE SAMOSATA
}

\author{
Matías Sebastián Fernandez Robbio* \\ Universidad Nacional de Cuyo
}

RESUMO: Espalhados em seis livros da Antologia Grega acham-se sessenta e quatro epigramas atribuídos a Luciano de Samósata. Analisase aqui uma seleção de catorze deles, que apresentam períodos hipotéticos:X.30,X.31,X.35,X.41,X.45,XI.129,XI.274,XI.396,XI.404, XI.420, XI.430, XI.431, XI.434, XVI.163. Focar-nos-emos no estudo dessa estrutura sintática a partir de três perspectivas: a morfologia e a sintaxe da língua grega, a prosódia e o uso retórico dos períodos hipotéticos, ao qual o autor recorre como estratégia argumentativa.

PALAVRAS-CHAVE: Luciano de Samósata; sintaxe grega; prosódia grega; métrica grega; epigrama.

\section{Acerca del corpus}

ompilada a fines del X en el mundo bizantino, la Antología Palatina ${ }^{1}$ ha permitido conservar epigramas atribuidos a casi trescientos cuarenta

\footnotetext{
^matias_fr@hotmail.com

${ }^{1}$ Las primeras antologías de poesía griega de las que se tiene noticia datan de la

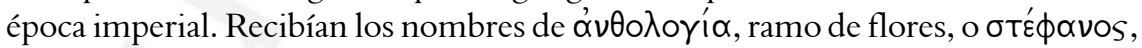
corona, haciendo referencia al carácter selecto de los poemas que compilaban. La primera antología de la que se tiene conocimiento es la Corona de Meleagro compilada en el 70 a.C., seguida por las de Filipo de Tesalónica en el siglo I y Diogeniano en el siglo II, hasta llegar a la de Agatías en tiempos de Justiniano. Durante el siglo X, Constantino Céfalas, basándose en estas antologías publicadas varios siglos antes, publicó una antología temática, cuyo orden sirvió de base para el de la Antología Palatina (en adelante $A P$ ). Ésta, a su vez, fue compilada durante el siglo
} 
poetas que escribieron a lo largo de quince siglos de la literatura griega. Dispersos en seis de sus dieciséis libros, incluyendo la Antología Planudea, ${ }^{2}$ se encuentran cincuenta y tres epigramas que quizás hayan sido escritos por Luciano de Samosata (Samosata, Siria, 125-181).

La totalidad de su obra incluye no sólo declamaciones sofísticas, diatribas, tratados y diálogos sino también estos pocos epigramas. El índice de la $A P$ asegura que, de los cincuenta y tres epigramas, Luciano escribió cuarenta e incluye otros trece epigramas entre corchetes atribuidos a otros autores que podrían haber sido escritos por él:

Lucianus. VI, 17, [20], 164. VII, 308. IX, 74], 120, 367.X, 26-29, [30], 31, 35-37, 41, 42, [45, 58, 107, 122].XI, [10, 80, 81, 129, 239], 274, 396, 397, 400-405, 408, 410, [420], 427-436. XVI, 154, 163, 164, $238 .{ }^{3}$

La tradición textual de la obra de Luciano ha tornado este conjunto de poemas en un problema para la filología contemporánea. Un epigrama, que funcionaría como prólogo de la obra del samosatense, ha sido conservado en los códices de Focio (Marcianus 450 y 451) y ha sido anexado al Anthologiae Graecae Appendix como epigrama III.132. Otros epigramas han sido conservados en algunos manuscritos más recientes de la obra de Luciano (Urbinasgraecus1 20, Riccardianus 25, Laurentianus 57.1). En total, sumando los epigramas conservados en los mss. Palatinus 23 de la $A P$ y Marcianus 481 de la $A P l$, aunque exceptuando el que ha sido conservado por Focio, un total de 63 epigramas aparecen en la $A G$, sobre todo en los libros X y XI.

$\mathrm{X}$, aunque no se tuvo conocimiento de ella hasta 1606 o 1607 , cuando fue descubierta en la biblioteca del Palacio de Heidelberg por Claude Saumaise, un francés más conocido por la versión latina de su nombre, Salmasius. Si bien este estudioso hizo copias del manuscrito y las hizo circular bajo el nombre de Anthologia inedita, el texto completo recién fue publicado en 1776 en la Analecta veterum poetarum Graecorum de Richard François Philippe Brunck.

${ }^{2}$ Por su parte, la Antología Planudea (en adelante $A P l$ ) fue compilada por Máximo Planudes, un monje de Constantinopla, a principios del siglo XIV. Tras la caída del Imperio Romano de Oriente, el manuscrito original fue conservado gracias a quienes migraron de Constantinopla a Italia. El texto fue copiado originalmente por Constantinus Lascaris, pero fue Janus Lascaris, un discípulo suyo, quien se encargó de hacerlo imprimir en Florencia en el año 1494 bajo el título Anthologia epigrammatum Graecorum. La compilación de la $A P$ con la $A P l$, editada como un décimo sexto libro de la $A P$ que incluye únicamente aquellos epigramas que no se repiten en ambas, se denomina Antología Griega (en adelante $A G$ ).

${ }^{3}$ Cf. Cougni, op. cit., p. 686. 
Esto ha causado problemas a la tarea editorial, que se evidencian en las decisiones tomadas por los editores de la obra de Luciano. Jacobitz, coincidiendo parcialmente con el índice de la edición de Cougni, incluye únicamente cincuenta y tres en su editio maior. En la edición oxoniense, Mac Leod incluye 63 epigramas, pues edita como espurio el que conservó Focio, mientras que en la edición de la Loeb Classical Library se edita únicamente ese mismo epigrama, conservado también en algunos manuscritos menores de Luciano, pero para los restantes se envía al lector a la edición de Paton de la $A G$ compuesta por cinco volúmenes de esa colección. ${ }^{4}$

Hasta una fecha reciente, los únicos estudios específicos acerca de este corpus pertenecen a Setti (1892), Helm (1927), Baldwin (1975) y Gómez Cardó (2008). La producción epigramática de Luciano ha permanecido olvidada en general por los historiógrafos y los críticos literarios. Esto ha sido motivado por la consideración común de que la totalidad de los epigramas son espurios o carentes de interés. Quienes sostienen tal opinión argumentan que estos poemas podrían haber sido escritos por Lucilio o algún otro Luciano del siglo $\mathrm{IV}^{5}$ Otra razón importante de duda acerca de la autoría del samosatense se debe a que estos textos no están incluidos en gran parte de los manuscritos de las obras del autor. ${ }^{6}$ Sin embargo, "los temas y los procedimientos empleados por Luciano en otras obras suyas coinciden con los de los epigramas, y éstos, a su vez, reproducen los empleados en otros epigramas satíricos (...)".7

Del corpus total de epigramas, catorce presentan períodos hipotéticos: X.30, X.31, X.35, X.41, X.45, XI.129, XI.274, XI.396, XI.404, XI.420, XI.430, XI.431, XI.434, XVI.163. Esta ponencia se propone analizar estos textos, comúnmente ignorados al estudiar la obra del samosatense, desde tres perspectivas: en primer lugar, la morfología y la sintaxis de la lengua griega; en segundo, la prosodia y en tercer lugar, el valor retórico de los períodos hipotéticos que el autor construye como estrategia argumentativa.

\footnotetext{
${ }^{4}$ Cf. Gómez Cardó, op. cit., p. 38.

${ }^{5}$ Cf. Cantarella, op. cit., p. 298.

${ }^{6}$ Cf. Gómez Cardó, op. cit., p. 40.

${ }^{7}$ Cf. Gómez Cardó, op. cit., p. 40.
} 


\section{Selección y traducción}

El epigrama X.30 es un dístico elegíaco compuesto por una oración compleja por coordinación:

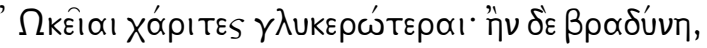

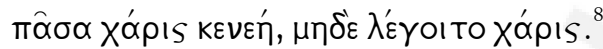

Es evidente el paralelismo de la secuencia adjetivo-sustantivoadjetivo existente en los dos versos: en el primero finaliza antes de la diéresis y en el segundo, en la cesura pentemímera. El segundo coordinado es un período hipotético universal de presente cuya apódosis está compuesta por dos coordinados. La estructura lógica de este epigrama es deductiva: se afirma un enunciado general sobre un sujeto determinado y se postula que eso no sería lo que es si se modificase uno de sus atributos.

El epigrama X.31 también es una oración compleja por coordinación en la que cada uno de los versos del dístico elegíaco es uno de los coordinados:

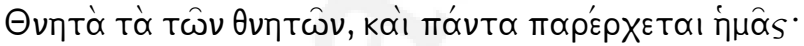

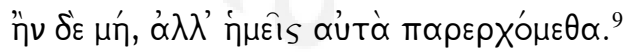

El primero de los versos también está compuesto por dos coordinados de tipo enunciativo. El segundo de los versos es un período hipotético universal de presente. Este epigrama también se basa en una lógica deductiva: parte de una tautología, infiere un enunciado general que se encuentra en el segundo coordinado del primer verso, lo niega en la prótasis y postula una conclusión. Es interesante notar que en el primer enunciado y en la apódosis del período hipotético se mantiene el mismo verbo pero se produce una inversión: lo que en uno es sujeto es objeto directo en el otro y viceversa. El período hipotético es la estructura lógica que le permite al autor producir esta inversión y persuadir por medio de ella a pesar de que no sea válida lógicamente.

\footnotetext{
8 "Goces rápidos son más agradables; pero, si llega tarde,/ todo goce es vacío y no debería ser llamado 'goce" (todas las traducciones de los epigramas citados pertenecen al autor de este trabajo).

9 "Mortales son las cosas de los mortales y todas andan a nuestro lado; y si no, no obstante, andamos junto a ellas”.
} 
El epigrama X.35 está compuesto por dos dísticos elegíacos. Es una oración compleja por coordinación:

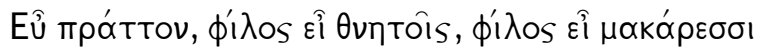

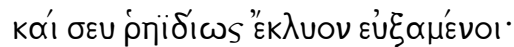

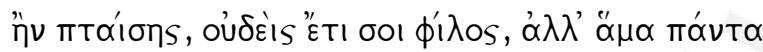

'EX

En el primer coordinado se encuentran un participio de presente y un participio de aoristo que pueden ser traducidos con matiz temporal o condicional como prótasis a pesar de no serlo en el texto griego. El segundo dístico elegíaco es efectivamente un período hipotético universal de presente cuya apódosis está compuesta por dos coordinados. Es interesante notar el paralelismo existente entre el final de la primera construcción de participio que puede ser traducida como una prótasis y el final de la prótasis del período hipotético, pues ambos finales coinciden en la cesura trihemímera. La estructura del epigrama pretende parecer un silogismo lógicamente válido, aunque no lo es, pues no cumple con las condiciones formales del modus ponens ni del modus tollens: el autor afirma una premisa y su consecuencia y luego pretende negar la consecuencia negando la condición. El destinatario del epigrama es una segunda persona, el lector.

El epigrama X.41 está compuesto por cuatro dísticos elegíacos. El primero de ellos es una oración compleja por coordinación, el segundo es una oración simple incluyente y el tercero y el cuarto son una oración compleja con modificador de modalidad condicional: el tercer dístico es la prótasis y el cuarto, la apódosis:

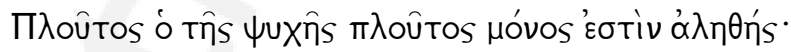

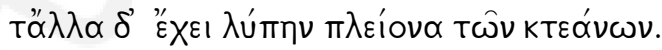

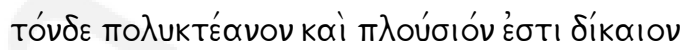

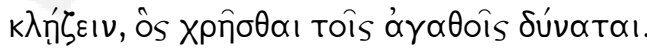

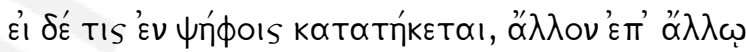

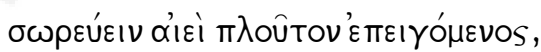

\footnotetext{
10 "Mientras te va bien, eres querido por los mortales, eres querido por los dioses/ y, cuando les suplicas algo, rápidamente te escuchan./ Si caes en desgracia, ya no tienes ningún amigo sino que al mismo tiempo/ todo es hostil, porque cambia con los tumbos de Fortuna".
} 


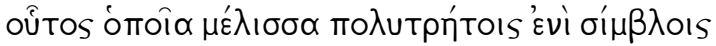

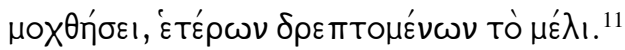

Los dos primeros dísticos son los enunciados que el autor utiliza como sustento para el período hipotético real que propone. Tanto en la prótasis como en la apódosis hay construcciones de participio: la primera funciona como modificador directo de un pronombre indeterminado y la segunda es una construcción de genitivo absoluto. En cuanto al contenido del epigrama, resulta muy interesante el modo en que el autor se refiere a las abejas: ellas no son un ejemplo de trabajo duro, esfuerzo y entrega a la comunidad, sino que aparecen como trabajadoras compulsivas incapaces de disfrutar lo que producen.

El epigrama X. $45^{12}$ también está compuesto por cuatro dísticos elegíacos dirigidos a una segunda persona, el lector:

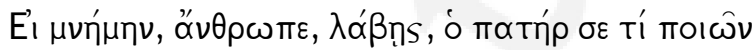

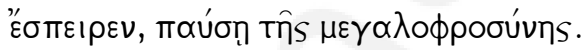

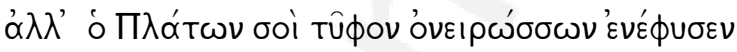

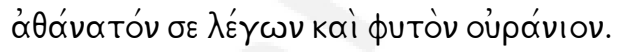

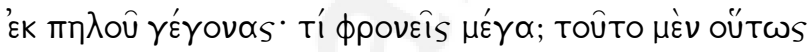

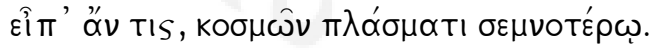

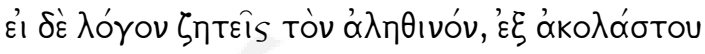

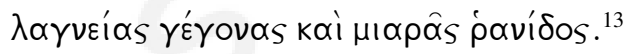

El primero de ellos es un período hipotético eventual y el cuarto de ellos es un período hipotético real. El primer período está compuesto por una prótasis basada en un dato conocido por la experiencia y una

\footnotetext{
11 "La riqueza del alma es la única verdadera riqueza,/ pues las otras causan más desgracia que las posesiones./ Es justo llamar abundante en posesiones y rico/ a quien sabe utilizar sus bienes./ Pero si alguien se consume en sus cuentas,/ esforzándose en acumular siempre riqueza, una sobre otra,/ éste, como abeja en colmena de muchas celdas,/ se fatigará mientras otros colectan la miel”.

12 Este epigrama ha sido excluido en la edición crítica de la obra completa de Luciano elaborada por MacLeod.

13 "Si recuerdas, hombre, de qué modo tu padre/te engendró, modera tu arrogancia./ Pues Platón, que tenía poluciones en sus sueños, hizo nacer la vanidad en ti/ al llamarte inmortal y engendro celestial./ Has nacido del barro. ¿Por qué eres tan engreído? Esto/ así te lo diría alguien embelleciéndolo./ Pero, si buscas una palabra verdadera, has nacido/ de la lascivia licenciosa y de una gota impura".
} 
apódosis de evidente carácter exhortativo a pesar de estar en modo subjuntivo. En el comienzo del quinto y del octavo verso existe un paralelismo que llega hasta la cesura pentemímera. La prótasis del segundo período hipotético se extiende hasta la diéresis del séptimo verso, donde comienza la apódosis. Es curioso el hecho de que los dos modificadores condicionales presentes en este epigrama no sean modificadores del dictum, sino del modus, pues ellos no condicionan el cumplimiento de lo que se afirma en el núcleo oracional.

El epigrama XI.129 está compuesto por dos dísticos elegíacos y cada uno de ellos es una oración:

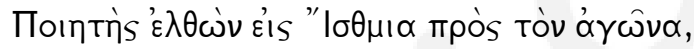

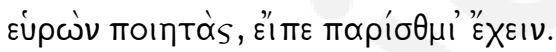

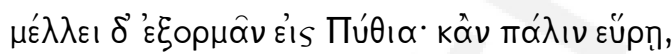

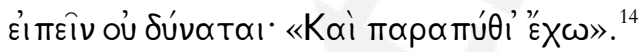

La segunda de ellas es una oración compleja por coordinación. Su segundo coordinado es un período hipotético universal de presente. Este epigrama está basado en un juego de palabras: el personaje viaja a Istmia y cuando se encuentra con otros poetas afirma que tiene glándulas "parístmicas", es decir, amígdalas; pero no es capaz de afirmar que tiene glándulas "parapitias" cuando viaja a Pitia pues ellas no existen. El período hipotético presenta la situación del poeta al encontrarse con otros y ser incapaz de afirmar tal cosa.

El epigrama XI.274 está compuesto por dos dísticos elegíacos:

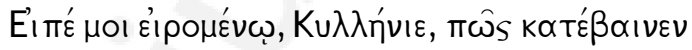

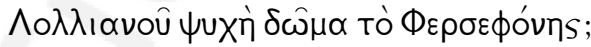

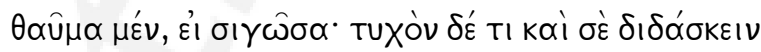

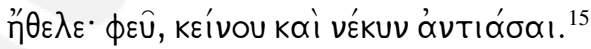

El primero es una oración simple incluyente de una proposición sustantiva icónica. El segundo es una oración compleja con un modificador

\footnotetext{
14 "Un poeta que iba hacia los Juegos Ístmicos, al certamen,/ cuando se encontró con otros poetas, dijo que tenía paristmitis./ Está por partir hacia los Juegos Píticos; y si de nuevo se los encuentra,/ no puede decir: "También tengo parapititis"”.

15 "Dime a mí que te pregunto, Cilenio: ¿de qué modo descendió/ el alma de Loliano al palacio de Perséfone?/ Cosa asombrosa, si callaba: pero tal vez incluso a ti quería enseñarte/ alguna cosa. iAy del que se encuentre con aquél incluso muerto!"
} 
condicional. Este período hipotético es muy irregular: en primer lugar, el orden lógico de sus partes está invertido; en segundo lugar, el verbo de la prótasis no está conjugado en una forma personal, sino que es un participio y en tercer lugar, la apódosis no tiene ningún verbo.

El epigrama XI.396 está compuesto por dos dísticos elegíacos. Cada uno de ellos es una oración compleja por coordinación:

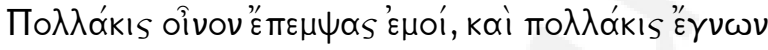

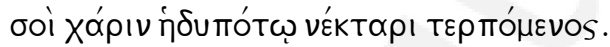

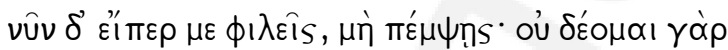

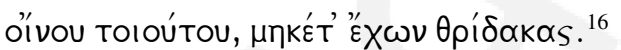

La segunda oración está compuesta por dos coordinados. El primero de ellos es un período hipotético real aparentemente paradójico. La prótasis se extiende hasta la cesura pentemímera y la apódosis se extiende hasta la diéresis. El segundo coordinado es una mordaz justificación de la apódosis. Desde un punto de vista retórico, la función de la prótasis es simplemente suavizar la ironía del último enunciado del epigrama.

El epigrama XI.404 está compuesto por tres dísticos elegíacos. Los dos primeros son una oración compleja por coordinación y el último es un período hipotético:

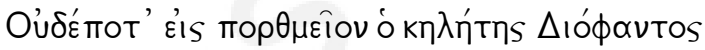

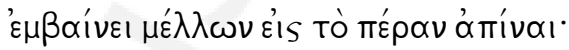

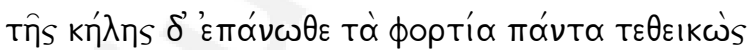

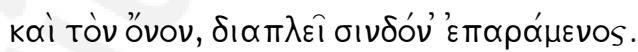

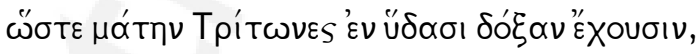

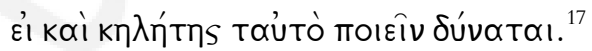

Los cuatro primeros versos presentan una situación general que sirve como base para el último dístico. El orden lógico del período está

\footnotetext{
16 "Muchas veces me enviaste vino y muchas veces te di/ las gracias deleitado por el dulce néctar./ Ahora si me quieres, no me lo envíes; pues no necesito/ tal vino ahora que ya no tengo más lechugas".

17 "El jorobado Diofanto jamás se embarca en un navío/ cuando quiere llegar a la otra orilla;/ por el contrario, deposita sobre su joroba toda la carga,/ incluso su burro, y navega izadas las velas./ Así que en vano los Tritones tienen fama en las aguas/ si incluso un jorobado puede hacer lo mismo".
} 
invertido. Su apódosis se refiere a seres acuáticos mitológicos utilizados como comparación.

El epigrama XI.420 es un único dístico elegíaco:

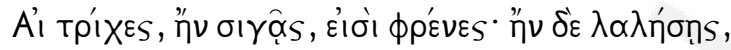

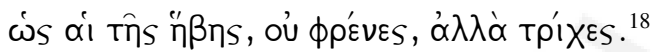

A pesar de su brevedad, su estructura sintáctica no es simple: es una oración compleja por coordinación y cada uno de sus coordinados está compuesto por un modificador condicional y un núcleo oracional. El autor se vale de estos períodos hipotéticos universales de presente para mostrar cómo un mismo atributo personal puede representar dos cosas distintas si varía el comportamiento de los sujetos.

El epigrama XI.430 es un período hipotético real expresado en un dístico elegíaco:

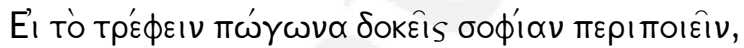

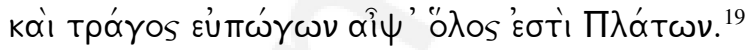

Su primer verso es la prótasis del período y su último verso, la apódosis. El tono mordaz de la apódosis de este epigrama es reforzado por la utilización de un verbo conjugado en el presente del modo indicativo y no en algún tiempo del modo subjuntivo.

El epigrama XI.431 también es un período hipotético real compuesto en un único dístico elegíaco:

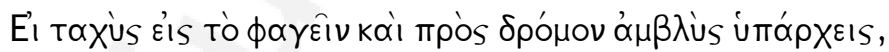

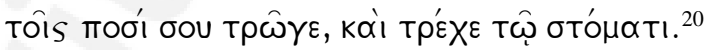

También aquí el primer verso es la prótasis y el segundo es la apódosis. Los dos versos de este epigrama presentan quiasmos: en el primer verso se invierte la secuencia de un adjetivo y una construcción preposicional y en el segundo, la secuencia de un dativo instrumental y un imperativo. En ambos aparece un coordinante copulativo como eje de los quiasmos.

\footnotetext{
18 "Los cabellos, si callas, son sensateces; pero si parloteas,/ son como los de la juventud, no sensateces, sino cabellos".

19 "Si crees que dejarte crecer la barba te inviste de sabiduría,/ también un macho cabrío bien barbudo es, de inmediato, todo un Platón".

20 "Si comienzas rápido a comer y lento a correr,/ come con tus pies y corre con tu boca”.
} 
En el epigrama XI.434 también se encuentra un período hipotético expresado del mismo modo, en un único dístico elegíaco cuya prótasis es el primer verso y cuya apódosis es el segundo verso:

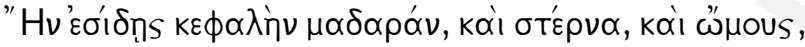

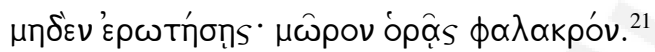

En el primer verso el autor coordina elementos de modo polisindético mientras que en el segundo sólo utiliza un punto alto. Este epigrama exhorta a no hacer preguntas si se ve a un calvo pues la calvicie era un símbolo de sabiduría y muchos adeptos a las nuevas religiones orientales raspaban sus cabezas, a pesar de que en muy pocos casos fueran sabios (cf. Luc., Acerca de los sacrificios \$14).

El epigrama XVI.163 es una oración compleja por coordinación cuyo segundo coordinado es un período hipotético irreal de presente:

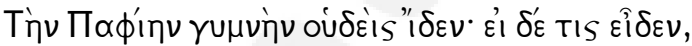

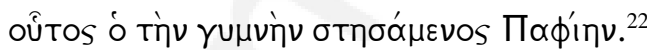

La diéresis del primer verso marca el comienzo de la prótasis del segundo coordinado, que se extiende hasta el final del verso. El último verso es la apódosis de este período. Este epigrama parte de una enunciación y utiliza un período hipotético para plantear una situación irreal que sólo podría haber acontecido bajo una determinada condición.

\section{Comentario morfológico y sintáctico}

A fin de facilitar el análisis de los períodos condicionales de estos epigramas, sus características morfosintácticas han sido sistematizadas de modo analítico en la siguiente tabla:

\footnotetext{
21 "Si ves una cabeza rapada, pecho y hombros,/ no preguntes: estás viendo a un calvo necio".

22 "A la Pafia nadie vio desnuda; pero si alguien la ha visto,/éste es el que erigió [la estatua de] la Pafia desnuda".
} 


\begin{tabular}{|c|c|c|c|c|c|c|}
\hline \multirow[t]{2}{*}{ Epigrama } & \multicolumn{2}{|c|}{$\begin{array}{l}\text { Orden de las partes } \\
\text { del período hipotético }\end{array}$} & \multirow[t]{2}{*}{ Subordinante } & \multicolumn{2}{|c|}{ Tiempos verbales } & \multirow{2}{*}{$\begin{array}{l}\text { Tipo de } \\
\text { período } \\
\text { hipot. }\end{array}$} \\
\hline & Prótasis & Apódosis & & Prótasis & Apódosis & \\
\hline X.30 & $1^{\mathrm{a}}$ & $2^{\mathrm{a}}$ & $\dddot{\eta \nu}$ & Pte. MSubj & Pte. MInd & Univ. Pte. \\
\hline X.31 & $1^{\mathrm{a}}$ & $2^{\mathrm{a}}$ & "ॄv & - & Pte. MInd & Univ. Pte. \\
\hline X.35 & $1^{\mathrm{a}}$ & $2^{\mathrm{a}}$ & "ॄv & Pte. MSubj & - & Univ. Pte. \\
\hline X.41 & $1^{\mathrm{a}}$ & $2^{\mathrm{a}}$ & हो & Pte. MInd & Fut. MInd & Real \\
\hline \begin{tabular}{|l} 
X. 45 \\
v. $1-2$ \\
\end{tabular} & $1^{\mathrm{a}}$ & $2^{a}$ & हो & Aor. $2^{\circ}$ MSubj & Aor. MSubj & Eventual \\
\hline $\begin{array}{l}\text { X. } 45 \\
\text { v. } 7-8\end{array}$ & $1^{\mathrm{a}}$ & $2^{\mathrm{a}}$ & हो & Pte. MInd & Perf. MInd & Real \\
\hline XI.129 & $1^{\mathrm{a}}$ & $2^{\mathrm{a}}$ & Kớv & Aor. $2^{\circ} \mathrm{MSubj}$ & Pte. MInd & Univ. Pte. \\
\hline XI.274 & $2^{\mathrm{a}}$ & $1^{\mathrm{a}}$ & हो। & Participio Pte. & - & ¿Real? \\
\hline XI.396 & $1^{\mathrm{a}}$ & $2^{\mathrm{a}}$ & - & Pte. MInd & Pte. MInd & Real \\
\hline XI.404 & $2^{\mathrm{a}}$ & $1^{\mathrm{a}}$ & - & Pte. MInd & Pte. MInd & Real \\
\hline \begin{tabular}{|l|} 
XI. 420 \\
V. 1 \\
\end{tabular} & $1^{\mathrm{a}}$ & $2^{\mathrm{a}}$ & "nv & Pte. MSubj & Pte. MInd & Univ. Pte. \\
\hline \begin{tabular}{|l|} 
XI.420 \\
v. $1-2$ \\
\end{tabular} & $1^{\mathrm{a}}$ & $2^{\mathrm{a}}$ & ח๊v & Perf. MSubj & - & Univ. Pte. \\
\hline XI.430 & $1^{\mathrm{a}}$ & $2^{\mathrm{a}}$ & हो। & Pte. MInd & Pte. MInd & Real \\
\hline XI.431 & $1^{\mathrm{a}}$ & $2^{\mathrm{a}}$ & हो & Pte. MInd & Pte. MImp & Real \\
\hline XI.434 & $1^{\mathrm{a}}$ & $2^{\mathrm{a}}$ & $\eta$ & Pte. MSubj & Aor. MSubj & Eventual \\
\hline XVI.163 & $1^{\mathrm{a}}$ & $2^{\mathrm{a}}$ & हो & Imperf. MInd & - & Irreal Pte. \\
\hline
\end{tabular}

Si bien el corpus está compuesto por catorce epigramas, hay en total dieciséis períodos hipotéticos. Catorce de estos mantienen el orden lógico según el cual la construcción debe ir encabezada por la prótasis y seguida por la apódosis. Además, diez de los dieciséis períodos pertenecen a oraciones complejas por coordinación, mientras que sólo seis son oraciones independientes dentro de los epigramas: X.41, X.45 v. $1-2$, X.45 v. 7-8, XI.404, XI.430, XI.431.

Con respecto a los subordinantes utilizados por Luciano, ह่। aparece en siete epigramas; $\dddot{\eta} \nu$, en seis y $\stackrel{\alpha}{v}$, en uno. Se verifica una correspondencia parcial entre los subordinantes que las gramáticas griegas señalan para cada tipo de período condicional. No se registra ningún caso de '£óv $\nu$, evitado quizá por razones métricas.

Los verbos utilizados en los períodos hipotéticos no siempre respetan la correlación verbal que los gramáticos postulan como regular en los períodos hipotéticos griegos. Incluso se encuentra una forma nominal del verbo en uno de los períodos ( $c f$. XI.274 v. 3). Las combinaciones de tiempos encontradas son las siguientes: 


\begin{tabular}{|c|c|c|c|c|}
\hline \multicolumn{2}{|c|}{ Prótasis } & \multicolumn{2}{|c|}{ Apódosis } & \multirow[t]{2}{*}{ Registros } \\
\hline Modo & Tiempo & Modo & Tiempo & \\
\hline \multirow[t]{6}{*}{ Indicativo } & \multirow[t]{5}{*}{ Presente } & \multirow[t]{4}{*}{ Indicativo } & Presente & 2 \\
\hline & & & Futuro & 1 \\
\hline & & & Imperfecto & 1 \\
\hline & & & Perfecto & 1 \\
\hline & & Imperativo & Presente & 1 \\
\hline & Imperfecto & \multicolumn{2}{|l|}{-} & 1 \\
\hline \multirow[t]{6}{*}{ Subjuntivo } & \multirow[t]{3}{*}{ Presente } & Indicativo & Presente & 2 \\
\hline & & Subjuntivo & Presente & 1 \\
\hline & & - & & 1 \\
\hline & Perfecto & - & & 1 \\
\hline & \multirow[t]{2}{*}{ Aoristo $2^{\circ}$} & Indicativo & Presente & 1 \\
\hline & & Subjuntivo & Aoristo & 1 \\
\hline Participio & Presente & - & & 1 \\
\hline \multicolumn{2}{|l|}{-} & Indicativo & Presente & 1 \\
\hline
\end{tabular}

Tal vez el problema de la irregularidad de las correlaciones pueda ser resuelto aceptando la propuesta de Higgins acerca de la existencia de un "«standard late Greek», (...) una lengua que mezclaría una sintaxis dialectal y el vocabulario jónico-ático de la koiné", ${ }^{23}$ pues efectivamente se verifica una sintaxis no clásica y es posible encontrar vocabulario jónico-ático en los epigramas de este autor.

\section{Comentario prosódico}

Luciano compuso sus epigramas teniendo en cuenta no sólo aspectos gramaticales de la lengua griega sino también aspectos prosódicos. La importancia de estos últimos consiste en que ellos son fundamentales para la formación en el lector u oyente de una percepción de agrupamiento.

Todos los epigramas del corpus analizado están formados por dísticos elegíacos que combinan pies dactílicos y espondaicos. Las distintas cesuras utilizadas no sólo tienen una intención prosódica, sino que también concuerdan con la distinción de construcciones. Algunas cesuras resaltan por el rigor formalista con el que han sido dispuestas. Marcan el fin del modificador condicional las cesuras trihemímera en

${ }^{23}$ Cf. Alsina, op. cit., p. 44. 
X.35 v. 1, heptemímera en X.45 v. 1 y trocaicas en XI.274 v. 3 y en XI.396 v. 3. En X.431 v. 2 la cesura marca el fin del primer coordinado del núcleo oracional del período hipotético.

Es necesario mencionar además que las diéresis bucólicas al final del cuarto pie de los hexámetros concuerdan con el final de construcciones sintácticas. Entre las más importantes, siete de ellas coinciden con el final de coordinados en oraciones complejas ( $c f . \mathrm{X} .30$ v. 1, X.35 v. 3, XI.129 v. 3, XI.274 v. 3, XI.396 v. 3, XI.420 v. 1, XVI.163) y una marca el fin de un modificador condicional y el comienzo de un núcleo oracional (cf. X.45 v. 7).

Resulta notable que los subordinantes $\varepsilon i$, ñv y ăv siempre llevan el ictus. Esto señala que la condicionalidad juega un papel tan importante en esos epigramas que merece ser siempre acentuada. Por esta razón, los subordinantes incluso encabezan los versos en la mayoría de los epigramas ( $c f$. X.31, X.35, X.41, X.45 v. 1-2, X.45 v. 7-8, XI.404, X.430, $\mathrm{X} .431, \mathrm{X} .434)$. Esto permite aventurar que quizás en la lengua griega se dé el mismo fenómeno que Hernández Díaz registra en la prosodia de los condicionales en la lengua castellana: "que el reajuste tonal sí actúa como límite prosódico demarcativo entre la oración condicional y sus contextos" (2003,p. 568). ${ }^{24}$

Es también interesante notar que se encuentran algunos versos con rima leonina entre sus hemistiquios ( $c f$. XI.420 v. 2, XI.430 v. 1 y 2 , XVI.163 v. 1 y 2 ).

\section{Comentario retórico}

Luciano compone sus epigramas valiéndose de una gran variedad de recursos. Se evidencia un uso cuidadoso y rico de adjetivos, una intención dialógica con el lector, referencias mitológicas y a personajes históricos y juegos de palabras.

Varios epigramas redactados en segunda persona están dirigidos al lector (cf. X.35, X.45, XI.396, XI.420, XI.430, XI.431, XI.434). Este recurso permite llamar su atención y hacer que se sienta interpelado. Dos enunciados son interrumpidos por la introducción de un vocativo que presenta al interlocutor del poeta ( $c f$. X.45 v. 1, XI.274 v. 1). En el primer caso, dirigido a un tú, este recurso evidentemente pretende interpelar al lector, sorprenderlo y persuadirlo. En el segundo caso, la

${ }^{24}$ Cf. Hernández Días, op. cit., p. 568. 
referencia a un dios quizá sirva para parodiar con un asunto de baja importancia los epigramas votivos de otros poetas.

En concordancia con el estilo de la poesía epigramática alejandrina, las alusiones mitológicas sirven como comparaciones (cf. XI.404 v. 5) o como motivo para una redacción erudita (cf. XVI.163). Luciano también sabe aprovechar la figura de personajes históricos famosos para componer sus epigramas, como muestra al referirse a la figura de Platón en dos epigramas. En uno de ellos se refiere a él para burlarse de sus teorías de las ideas y de la inmortalidad del alma ( $c f$. X.45 v. 2-4) y en el otro lo toma como modelo de sabiduría (cf. XI.430).

El poeta recurre también a juegos de palabras. En el epigrama XI.129 el autor toma una palabra existente, la descompone y reemplaza uno de sus componentes por otro. De este modo, crea una palabra sin significado para bromear utilizándola como la original aunque en circunstancias diferentes. En el epigrama X.430 invierte los instrumentos verdaderos de dos acciones para compensar la lentitud de una y la rapidez de la otra.

\section{Valor argumentativo de los períodos hipotéticos}

A pesar de haberlo intentado, no ha sido posible encontrar trabajos de investigación que propongan una lectura de los períodos hipotéticos desde los campos teóricos de la retórica y la pragmática. Por eso mismo, las siguientes afirmaciones son simples hipótesis que han guiado este trabajo y que parece posible confirmar en el marco de su limitado corpus.

Hasta aquí la lectura de estos epigramas ha sido presentada de modo analítico desde diferentes perspectivas gramaticales. Sin embargo, se pretende demostrar cómo Luciano logra combinar las dimensiones formal y pragmática del lenguaje por medio del uso de una estructura sintáctica con la finalidad de persuadir al lector. Creemos que la elección de esta estructura puede ser justificada por dos razones. En primer lugar, esta estructura es particularmente persuasiva porque representa por medio del lenguaje el razonamiento lógico. Parte siempre de una premisa, a veces tácita, y luego formula un período hipotético que le permite concluir con una enunciación inesperada por el lector que no sólo lo sorprende sino que también lo invita a reflexionar en la mayoría de los casos.

En segundo lugar, el uso argumentativo de esta estructura se justifica por el hecho de que, según Lausberg, ${ }^{25}$ toda estructura sintáctica

${ }^{25}$ Cf. Lausberg, op. cit., p. 41. 
bipartita resalta la fuerza de cada una de las partes del dictum en la retórica literaria. De este modo, tanto las prótasis como las apódosis son enfatizadas en cada período hipotético. Este recurso es particularmente evidente en aquellos epigramas en los que las prótasis y las apódosis están en distintos versos (cf. X.30, X.41, XI.129, XI.430, XI.431, XI.434, XVI.163). Los demás epigramas en los que las prótasis finalizan en los mismos versos en los que comienzan las apódosis también presentan una estructura bipartita marcada por las cesuras. Por consiguiente, el análisis prosódico de los ictus, las cesuras y las diéresis antes presentado confirmaría este postulado de Lausberg.

Por último, en relación con la ubicación de los períodos hipotéticos dentro de los epigramas, se observa una tendencia a que ocupen el final de los mismos. El valor retórico de los períodos hipotéticos (y, en particular, de sus apódosis) está dado entonces como un refuerzo de las enunciaciones de estos acumenes, versos finales de los epigramas que de por sí ya se caracterizan por su agudeza en toda la literatura epigramática.

Teniendo todo esto en cuenta, es posible afirmar entonces que en los epigramas de Luciano analizados el período hipotético no es una simple estructura sintáctica, sino que es un recurso retórico que intenta persuadir de acuerdo con el modo demostrativo de la argumentación formal y que siempre es construido con características y en posiciones distintivas.

Este resultado lleva a la formulación de nuevos interrogantes tanto en el ámbito de la sintaxis como en el de la retórica. En relación con lo primero, es necesario indagar si existe una relación entre la prosodia y la sintaxis que fije patrones a la construcción de ciertas estructuras sintácticas en la poesía en verso. En relación con lo segundo, cabe preguntarse si la ubicación de los períodos hipotéticos que aquí se ha verificado es un recurso común a otros autores o si es propio de Luciano y si existen modos particulares de construcción de los períodos hipotéticos en otros géneros literarios en los que también sean usados como recursos retóricos.

\section{Bibliografía}

ALSINA CLOTA, J. Introducción general. En: LUCIANO Obras: vol. I. Madrid: Gredos,1996, p. 7-69.

BALDWIN, B. The epigrams of Lucian. Phoenix, Toronto, n. 29, p. 311-315, 1975. CALSAMIGLIA BLANCAFORT, H.; VALLS, A. T. Las cosas del decir: manual de análisis del discurso. Barcelona: Ariel, 2004. 
CANTARELLA, R. La literatura griega de la época helenística e imperial. Buenos Aires: Losada, 1972.

COUGNI, E. (org.). Epigrammatum Anthologia Palatina: cum Planudeis et appendice nova (vol. 3). París: Firmin-Didot et Sociis, 1927.

DÜBNER, F. (org.). Epigrammatum Anthologia Palatina: cum Planudeis et appendice nova (vol. 1-2). París: Firmin-Didot et Sociis, 1888.

GÓMEZ CARDÓ, P. A propósito de algunos epigramas atribuidos a Luciano. Synthesis, La Plata, vol. 15, p. 37-57, 2008.

GUEVARA DE ÁLVAREZ, M. E. Compendio de sintaxis griega: teoría y práctica. Material didáctico para el curso "Actualización en lengua griega", preparatorio para la carrera de posgrado Especialización en Filología Clásica de la Universidad Nacional de Cuyo en Mendoza, Argentina. Mendoza: Facultad de Filosofía y Letras/ UNCuyo, 2007.

HELM, R. Lukianos: Epigramme. Realenzyklopädie der klassischen Altertumswissenschaft, Stuttgart, s. 1, 13.2, col. 1739-1740, 1927.

HERNÁNDEZ DÍAZ, B. Prosodia y gramática: delimitación de las oraciones condicionales en discurso semiespontáneo. Interlingüística (n. 14). Barcelona: Asociación de Jóvenes Lingüistas, 2003, p. 559-568.

KOVACCI, O. El comentario gramatical: teoría y práctica (2vol.). Madrid: Arco, 1990.

LAUSBERG, H. Elementos de retórica literaria: introducción al estudio de la filología clásica, románica, inglesa y alemana. Madrid: Gredos, 1975.

LO CASCIO, V. Gramática de la argumentación. Madrid: Alianza, 1998.

PATON, W. R. The Greek Anthology (6 vol.). London-Cambridge, Mass.: Harvard University Press, 1956-1958.

SARDI, L; ROSENBAUM, E; SILVENTI, C. Sintaxis griega: teoría y práctica (primera, segunda, tercera, cuarta, quinta $y$ sexta partes). Informes finales de proyectos de investigación. Mendoza: Facultad de Filosofía y Letras/ UNCuyo, 2000-2007.

SETTI, G. Gli epigrammi di Luciano. Rivista difilologia, Torino, n. 20, p. 161-200,1892. 